\title{
From Beginning to Irony
}

Self-Reflection in the Arts and Sciences by Alan Blum and Peter McHugh. Atlantic Highlands, NJ: Humanities Press, 1984 (159 pages)

Reviewed by

Kurt H. Wolff

Brandeis University

After reading the Introduction, I eagerly decided to accept the invitation to write about Self-Reflection in the Arts and Sciences. But reading on, the idea soon began to haunt me: How could I write about this book? My feelings toward it ran from fascination to despair over its opaqueness, irritation by its language, passionate expectation of a clue to what it was about, what it meant, what it told me about the world-in short my feelings ranged from being challenged by it to rejecting it, and wanting to withdraw my acceptance to be one of its reviewers.

For a while I thought I would juxtapose all the passages about selfawareness and see whether a common meaning could be gleaned from them, or more than one meaning, and how the relations between them could be articulated more clearly or explicitly than the authors had done. I will do this, but now, after a tentative interpretation of this book came to me, it will play a different role. At first I had hoped that beyond clarifying the meaning(s) of "self-reflection," the juxtaposing and relating might show me how to structure my report. But in carrying out this analytical step it gained a different significance, for now I think that what happened in the writing of this book is that the authors' thinking, which began with certain ideas about self-reflection, carried them to unanticipated phenomena and statements about them, most poignantly in the last chapter, "Rules and Principles." If this is so, it means that if one would do justice to those passages on self-reflection one must see them in the place they occupy in the development of the authors' thought. Let us try so to consider them-and to raise questions which are not, however, primarily context-related.

Self-reflection can be tentatively distinguished as speech that orients to its center (to its origin or principle), as speech that orients to the way it centers itself. (p. 3) 
This, from the Introduction, could also be put by saying that a person (rather than "speech") is self-reflective when talking ("speech") or thinking about how he or she has come to talk or think as he or she does; what, in this sense, the "center" of that speaking or thinking is. The authors continue:

This is not to say that inquiry needs to speak about its authoritative method by enumerating its procedures and assumptions, but rather that its routine accomplishment as a speech shows what it is speaking for (its conception of ideal discourse, of an ideal speaker) as an integral part of what it says. So we can begin to think about self-reflection as a speech that understands itself (which understands what it shows) in this way. (pp. 3, 4)

The authors claim, in other words, that speech is normative in the sense in which they think of normativity, namely, that it spontaneously and structurally-necessarily-demonstrates or witnesses the speaker's conception of what speech ought to be like. But what about lying, sarcasm, "false consciousness," irony (on which in the last chapter), in one word, what about the relation of speech to its topic, its listeners, its very speaker-to anything outside itself? But three pages later, "self-reflection in accord with Weber's conception of social action" is formulated as "action oriented to an order and governed thereby in its course" (p. 7). I have failed to find the source of this quotation, and indeed Weber defines social action as oriented to others, not to an "order"-an order which could, following the authors' earlier definitions of self-awareness, be that of one's speech itself.

In the third chapter, "The Social Order Problem: The Possibility of Language,"

Self-reflection is intelligible as the ideal discourse developed by consciousness about its relation to the lifeworld through its use of that very world. Self-reflection in this sense is language recollecting itself. (p. 35)

I read this to mean that when I speak I have to work with that with which my lifeworld supplies me, and that when I reflect on this relation between my setting and why I can say what about it, "language [is] recollecting itself." This is, again, speech "which understands what it shows," as we heard before, and raises the same question.

In the next chapter, "Self-Reflection I: Speech and Language," the authors point out that "reflection upon consciousness" must not be seen as "psychological," for

As we are using reflection, or self-reflection [are they synonymous?], such work is intended to capture the way in which consciousness reviews or recollects the analytic conditions deemed necessary for its intelligibility. (p. 45) 
But intelligibility to whom? To the person examining her or his own consciousness, assuming presumably-since the issue is analytic rather than psychological-that the findings can be universalized? But can they be? Can one claim them to be universal without grounding such a claim in a theory of intersubjectivity? Is it enough to say, as the authors do on the next page,

that the difference between our mind and his [the other's] mind loses its apparently essential character when we appreciate self-reflection as reflection upon the language that we share. (p. 46)

For what does "sharing" mean?

In the next statement about self-reflection-taking stock as of that stage in their development-the authors affirm its social character in the more generally understood sense.

Before we seek to discuss in detail the objection that such a mandate (for self-reflection) [as "the mode of life that shows an interest in addressing its source or foundation (in language)"] rests upon grounds that are ultimately conventional, we need to formulate self-reflection as a distinctive, socially oriented, and organized interest or need by envisaging its subjective interest, its course of action, its motivation, and its normative order (or rationality). In doing this, we will identify self-reflection as both similar to social action, by virtue of those conditions it shares with all practice, and as different, by virtue of its distinctive parameters, by virtue of what it is. The self-reflective actor in such a case must be a rational enquirer, but we have to understand the particular character and limits of this rationality. (p. 57)

More specifically, "self-reflection is practical action but practical action that is guided by an interest in relaying the grounds of a practice" (p. 62), that is, "either putting a foundation under ... or replacing one already laid by a new one" (Heidegger). But of which practice? The answer is that "within the confines of the actually existing practice, it seeks to recollect the 'deep need' to which the practice is assumed to answer" (p. 62).

These last two quotations are from Chapter 5, "Self-Reflection II: The Sociology of Knowledge," in which later the Other is more precisely defined: For self-reflection,

Other does not limit in the way a condition can limit, since conditions are taken into account by virtue of the Desire to exemplify something other [than] itself. Other is not that with which we establish a cognitive or interpretive relation and so it is not that which pertains to the achievement of evils but expresses the desire to address the quality of words in a way that supplies various interpretive relations to conditions with their rational character.

We have stipulated the self-reflective inquirer to be (1) a social actor, and so, (2) oriented in a subjective (meaningful, motivated) way, (3) to a 
valid and binding order and (4) to have reformulated that order, first as the lifeworld, subsequently as language. In saying that the inquirer is ruled by the order, we do not suggest that it "determines" him causally but that its "validity" is the result of whatever particular circumstances have invited him to find it "meaningful," where these circumstances make reference to his needs in the lifeworld or language. (p. 81)

These are among the (many) passages which I find irritating in their opaque precision and which have made me reconsider the agreement to write about this book. But I have come to believe it more useful to try following the authors less closely in detail than in the overall course of their adventure in the writing of their work. Thus, I must let this quotation go with only two remarks: (1) I do not know what the Other or other is they are talking about, but it doesn't sound like people. (2) As to the second paragraph: does "stipulated" mean that the authors have decided not to consider a self-reflective inquirer who is not a social actor? Or do they mean, not stipulate, but define, so that every self-reflective inquirer is a social actor? The self-reflective inquirer must be oriented to a valid and binding order: Could he or she-if we also allow for the possibilily that the orientation is antagonistic, which the authors to not explicitly exclude-not be so oriented? Again, the "stipulating" is confusing-yet it would not help if it were replaced by "defining." But why must the self-reflective inquirer reformulate that order (whether it be the inquirer's language or the social or political structure of his society) - the reformulation would seem to consist in the affirming or questioning or rejecting the order, but very probably not as a whole but only in part: but then, what do "first" and "subsequently" mean? Temporally? Logically? And why in either case this sequence?

In Chapter 6, "The Social Order Problem Again: The Adequacy of an Account," drawing on Garfinkel, Barthes, and Habermas, the authors "reformulate" "self-reflection as the deep need of speech to recollect-in the narrative action of discourse-its ground in language," which "raises the question of what adequate recollective work is (what adequate discourse is)." They answer "that adequate recollective work (adequate theory) will show its adequacy ... by drawing attention to the way in which it speaks as a recommendation of principle (of value)" (p. 109). The direction in which their modifying or reformulating self-reflection goes may have been seen for some time to be away from both the subject, the self-reflecting person, and the object, that which is reflected on (whether the subject itself or any other) and toward that which goes on between subject and object, reflecting itself-in the last quotation even to the point where the self has disappeared and been replaced by speech which has the deep need to recollect its ground in language, and which does so adequately - that is to say, which produces ade- 
quate theory-if it draws our (whose?) attention "to the way in which it speaks as a recommendation of principle (of value)."

They move on further: In Chapter 7, "Theorizing as Morally Oriented," they explicate the moral conception of "theorizing" that has been taking shape:

\begin{abstract}
All projects on self-reflection can be read as programs of morally oriented education. This is because the principled mode of self-reflective discourse that personifies [!] "adequate theory" in each program, no matter what its particular substance, is embodied in the discourse itself as both a recourse for its work and a latent possibility for the member. The principled mode of self-reflective discourse, which this work is intended to exemplify in its very own narrative, always and essentially pictures language as a normative order (as exemplified in the grasp of correct speaking displayed by the analyst) to which the member can orient. What is pictured is some version of a good relationship to languagesome version of language use or of discourse-as a valid and binding order. (p. 113)
\end{abstract}

"It has developed in our examination so far," the authors write on the next page (114), "that the deep need of theorizing is for an actor who is oriented to the lifeworld as an enforceably intelligible world that offers the possibility of principled speaking." Thus, the authors themselves are taking stock of where they have now arrived: away from self-reflective or speaking person and the content or object of speech (what the speech is about), at speech itself, discourse, theorizing, and its deep need "for an actor who is oriented to the lifeworld as an enforceably intelligible world that offers the possibility of principled speaking." What is this theorizing that needs a certain kind of actor who is oriented to an enforceably intelligible lifeworld (only one in crisis is not!) and thus offers the possibility of principled speech? As if it didn't take more than an enforceably intelligible lifeworld to make principled speech possible, where mass mediae render intelligible what without them might not be and where they expand the limits within which this intelligibility can be enforced. And for whom is intelligibility a problem anyway?

The authors arrive at the end of their development in the last chapter, "Rules and Principles," which despite its significant location I find probably more frustrating than any other. Here they start out from the "difference between the principled speaker and the ruleguided speaker" (p. 123) which they say

[is] difficult to grasp; indeed, it is the very difference between them that makes it so, since a rule cannot be consulted to resolve the difficulty. [And now they give a clue--possibly occurring to them only at this point-to their book:] The selfsame speech you now read, for example, reflects this difference as the authorial ground of our work, work that is principled in the sense that we know we cannot give a rule for reading 
the difference, and yet we expect that the difference will be grasped in the reading and that its work as principled speech will become accessible as the ground of our usage. (p. 123)

The difference between rule and principle is that between convention and necessity; and to come back to "the self-reflective actor," he or she

[must] be (endowed by us as) faithful to principle rather than to rule, if he is to be correct in a way that is other than accidental or conventional. The self-reflective actor has to be more than an interpreter or someone who applies rules correctly [this ought to be clear from earlier stages of the work]; a knower [same as self-reflective actor?] must be formulated as one who orients to the necessity of addressing necessity. (p. 129)

The authors thus are ever more deeply drawn to a moral view of the self-reflective individual; where self-reflection is moral and cannot exist otherwise. I find this a very appealing position, but it is based on no argument but only on the reader's or other authors' attraction to it, strengthened by attending to the authors' development toward this very position.

And their devotion to morality becomes more passionate yet:

One way to understand the problem of inquiry into our necessities [which rule or ought to rule our principles] is through an appreciation of its character as a search for rules to decide which behavior needs to be done. [Why not "decide what we must do?"] In this foreshortened view, we discover that to which we are committed - what we need to do-by discovering the rules that provide with clear and enforceable clarity for what we are to do. The problem of the principled actor's commitment to necessity is now transformed to exemplify the case of the competent actor's obligation to rule. (p. 139)

We observe that with this explication of the authors' moral commitment, the subject has come back into their discourse; but principled and self-reflective turn out to be identical.

To reassert the identity of the principled and self-reflective actor: (1) it is an idealization [I had thought it was a definition] rather than a description of (2) man rather than ego. This is the sense in which self is both a topic and a resource, because "self" is analytically understood as the necessities, limits, and imperatives of the human. The interchangeability of topic and resource [couldn't we say, of object and subject?] means only that being human is to ask after the foundation of the human. (p. 141)

Thus, the authors' road led them from self-reflection to preocc upation with the problem of what is human, indeed to an answer to this problem. The chapter and book end with a section on irony as "the way of life of the principled actor." "Imagine now," they write, "the 
theoretic man as the one exercised and animated by the problem of knowledge, i.e., by the problem of the desirable necessity of theorizing" (p. 142). Her or his fate, they concur with Hegel, is the "capacity to act without division" (p. 143), that is (I take it), exhaustively committed. Hence irony

as the capacity to act without being distracted by what (because of its necessity) needs to be suffered as real (inescapable) and, because of this, left behind. (p. 143)

The fully committed person thus offers us an instance of irony (which he or she, as fully committed, presumably is not aware of). Another way of depicting the same scene is to speak of the irony that "the ultimate truth is subject to discourse (its majesty must be adapted to human needs of grasping and expressing)," and, "of course, discourse is subject to the "ultimate truth"' (p. 143). Thus

[the] great insight of theorizing is to affirm our need to live enjoyably with this irony. That the absolute character of the "ultimate truth" is denied by its dependency upon discourse and by the need to be grasped and expressed, and that the absolute character of discourse (of the speaker, of the ego) is denied by its being en [sic] medias res. (pp. 143-144)

Yet the ultimate truth expresses itself "in various ways," which "are not ways external to the ultimate truth, but ways in which the ultimate truth is what it is" (p. 147). Where then is there a need or place for irony?

There is another meaning of irony (which the authors do not distinguish from the first):

That the ultimate truth needs discourse and is absolute points to a source of irony in my recognition that I am needed by the ultimate truth as much as it is needed by me. (p. 48)

Personifying irony (the authors tend to personify concepts and other phenomena, as we have seen before), they conclude that it

enjoys itself when it achieves the confidence needed to free itself from the guilt resulting from man's thinking of himself as being inadequate vis-à-vis the ultimate truth. (p. 150)

They thus end:

Is it not what irony sees with remarkable clarity: that the need to work out and develop is grounded in the need to defer in a way that we must accept with confidence rather than with suspicion? (p. 151)

II.

In what proceeds I have focused on two components of Self-Reflection in the Arts and Sciences: to what I referred to as the develop- 
ment of the authors' thinking about their topic and to what they say about their topic. My procedure has been to quote statements about self-reflection and to comment on them as if they were to be taken as statements rather than as stages of the authors' development or journey, as if they were not part of their story. And while I have certainly not done justice to these statements, I have done even less so to the story which this book is. The story I think is more important than the statements; and I shall try to show why.

I see the authors as allowing themselves to be carried by their enterprise, by its own dynamic, so that the topic they set out with, "selfawareness in the arts and sciences," changes unexpectedly and unexpectably. Let us reinspect the statements that tell the story.

Self-reflection is "speech that orients to its center" (p. 3), "that understands itself (which understands what it shows)" (p. 4); it "is intelligible as the ideal discourse developed by consciousness about its relation to the lifeworld through its use of that very world" (p. 35); it is "the way in which consciousness reviews or recollects the analytic conditions deemed necessary for its intelligibility" (p. 45); it is "reflection upon the language that wc share" (p. 16); it is "the mode of life that shows an interest in addressing its source or foundation (in language)" (p. 57); it is "a distinctive, socially oriented, and organized interest or need envisaging its subjective interest, its course of action, its motivation, and its normative order (or rationality)" (p. 57); it is "practical action, but practical action that is guided by an interest in relaying the grounds of practice" (p. 62); all projects on it "can be read as programs of morally oriented education. ... The principled mode of self-reflective discourse, which this work is intended to exemplify in its very own narrative, always and essentially pictures language as a normative order ... to which the member can orient" (p. 113; italics added). "The self-same speech you now read ... reflects this difference [between rule and principle] as the authorial ground of our work, work that is principled in the sense that we know we cannot give a rule for reading the difference, and yet we expect that the difference will be grasped in the reading and that its work as principled speech will become accessible as the ground of our usage" (p. 123). "The problem of the principled actor's commitment to necessity is now transformed to exemplify the case of the competent actor's obligation to rule" (p. 139). "The interchangeability of topic and resource means only that being human is to ask after the foundation of being human" (p. 141). Irony is "the capacity to act without being distracted by what (because of its necessity) needs to be suffered as real (inescapable) and, because of this, left behind" (p. 145). The "great insight of theorizing is to affirm our need to live enjoyably with this irony. That the absolute character of 'ultimate truth' is denied by its dependency upon discourse and by the need to be grasped and expressed, and that the 
absolute character of discourse ... is denied by its being en [sic] medias res" (pp. 143-144). "That the ultimate truth needs discourse and is absolute points to a source of irony in my recognition that I am needed by the ultimate truth as much as it is needed by me" (p. 148). Irony "enjoys itself when it achieves the confidence needed to free itself from the guilt resulting from man's thinking of himself as being inadequate vis-à-vis the ultimate truth" (p. 150), and "Is it not what irony sees with remarkable clarity: that the need to work out and develop is grounded in the need to defer in a way that we must accept with confidence rather than with suspicion?" (p. 151).

They begin with speech, move to consciousness, hence to the lifeworld, to interest and social action such as aims at relaying the grounds of its practice; from there in a larger leap to preoccupation with self-awareness as morally oriented education, which advocates principled discourse such as is exemplified in the very story they tell (or are being told) and to which they hope "the member can orient"; in fact, they expect the reader to grasp the difference between rule (following a rule) and principle (doing what is necessary), the principle being the only rule the competent actor ought to be obliged to follow; and the self, as the authors find themselves using the term, being both topic and resource, and being interchangeably topic and resource, tells them that this self as interchangeably analyzable and inspiring analysis is their clue to being human-human as searching "the foundation of the human"; but they appear to be unable to stand the rigor of this search without wrapping themselves in irony which they try to catch in several embraces: in the denial of the absoluteness of "ultimate" truth by its dependence on discourse and of that of discourse by its home in the lifeworld (media res); in the reciprocal need of ultimate truth (parallel to God) and "me" (parallel to person); in the victory of irony over the human guilt of feeling inadequate in front of ultimate truth; finally in the need to defer as grounding the need to work out and develop the claim that life makes-but then they end their search-for the time being, presumably - on a conciliatory if not imploring note by having to accept life's claim "with confidence rather than with suspicion."

The whole book thus is an exercise in devotion to self-awarenessthe topic the authors expected to discuss. Their devotion was not conditioned by the command to stick to the topic as they thought of it when they started on their enterprise. They allowed themselves to be carried where it would take them, but the excitement and the contagiousness of this experience are diminished by their previously mentioned and exhibited opaqueness, which I have tried to reduce in the second part of my response, and which appears to me to result from their incapacity to keep up with the pace of the journey that overtook them: They were too impatient or too weak. It is quite possible that my interpretation is a miss; but if so, at least part of the 
blame lies with that very opaqueness. This is a question that would need to be cleared in a discussion with the authors themselves. I have submitted my thesis. 